\title{
Experimental Study of Phenol as Biomass Tar Model Compound Gasification for Hydrogen
}

\author{
Danyang Zhang ${ }^{1,}$,Zhiguo Tang ${ }^{1, b}$ and Qingqing Liu ${ }^{1, \mathrm{C}}$ \\ ${ }^{1}$ School of Mechanical and Automotive Engineering, Hefei University of Technology, Hefei \\ 230009, China \\ azdynba@mail.hfut.edu.cn, btzhiguo@hfut.edu.cn, ${ }^{\mathrm{c} l i u q i n g q i n g 224 @ m a i l . h f u t . e d u . c n ~}$
}

\begin{abstract}
Keywords: Biomass; Tar; Phenol; Hydrogen;Porous ceramic foam
Abstract:Phenol,as one of the main constituents of biomass tar, was used to gasify for hydrogen in this paper. It was studied that the influences of the reaction temperature, steam / biomass (S / B), load and the preparationof the catalyst on the hydrogen yield, gasification efficiency and hydrogen concentration. In the experiment, the catalyst loading material is porous ceramic foam. The results indicate that the S/B molar ratio of 2,the temperature of $1073 \mathrm{~K}$ and the load of $8 \%$ provide favorable operating conditions for steam reforming of phenol so as to get the highest hydrogen yield,gasification efficiency and hydrogen concentration. And it was easier to produce hydrogen when catalyst was calcinated for 1 hour at $973 \mathrm{~K}$ and the porosity is $20 \mathrm{ppi}$.
\end{abstract}

\section{Introduction}

During the gasification process of biomass, tar is an inevitable by-product in the pyrolysis stage. The production of tar will not only cause energy waste, reduce efficiency of gasification, and pollute the environment and equipments, but also pose a certain hazard to human health ${ }^{[1]}$.Tar catalytic reforming is the most important step in the process of biomass pyrolysis and gasification ${ }^{[2]}$. Research on tar removal usually considers the use of model compounds, such as toluene $^{[3]}$,naphthalene ${ }^{[4]}$ and phenol ${ }^{[5]}$.

In viewof thecurrent researchon the impact of catalyst preparation conditions on the gasification process of phenol are relatively small. In this experiment, phenol and $\mathrm{Ni}$ are separately used as the tar model compound and the catalyst for the catalytic reforming of phenol vapor in the experimental platform. The catalyst loading material is porous ceramic foam. The orthogonal experimental method is adopted to reveal the influence of different reaction conditions and varied preparation conditions of the catalyst on the phenol gasification to produce hydrogen.

\section{Experimental materials and set-up}

In the experiment, phenol is used as the model compound of tar and the nickel-based catalyst is used to catalyze steam reforming of phenol in reactor ${ }^{[6]}$.The catalyst loading material isporous ceramic foam made of silicon carbide.

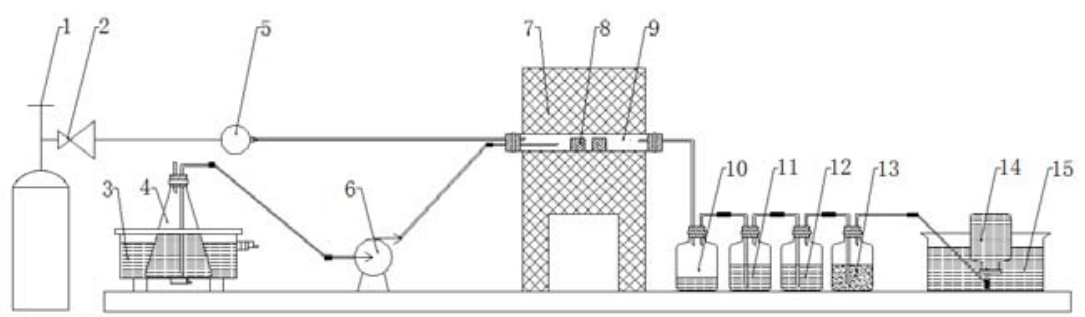

1 nitrogen bottles; 2 pressure reducing valve; 3 water-bath heater; 4 conical flask; 5 rotameter; 6 syringe pump; 7 electric furnace; 8 nickel-based catalyst; 9 quartztube; 10 safety bottle; 11 ethanol liquid; 12 water bottle; 13 desiccant; 14 cylinder; 15 flume

Figure 1 Experimental set-up for phenol steam reforming

The schematic of the experimental apparatus was shown in Fig. 1.The major equipment is the electric furnace and the evaporator consisted of the water-bath heater and the conical flask. Aqueous solution of phenol well mixed in the conical flask was heated by the water bath heater and then was introduced by the syringe pump into the quartz tube in the formation of gas to react. 


\section{Experimental results and discussion}

\section{Influence of Reaction Temperature, S/B and Load on the Experimental Results}

S/B and load on productivity of hydrogen, gasification efficiency and hydrogen concentration in the first part of this experiment. Restricted by many factors in the investigation, the orthogonal experiment is performed to investigate the influences of reaction conditions on the results, and the catalyst should be produced under same the preparation condition. The experimental scheme and experimental results are shown in table 1.

Table 1Experimental results of different reaction conditions

\begin{tabular}{|c|c|c|c|c|c|c|c|c|c|c|c|c|}
\hline \multirow{3}{*}{$\begin{array}{l}\text { Experiment } \\
\text { number }\end{array}$} & \multirow[t]{3}{*}{ Temperature(K) } & \multirow[t]{3}{*}{$\mathrm{S} / \mathrm{B}$} & \multirow[t]{3}{*}{ Load } & \multicolumn{3}{|c|}{$\begin{array}{l}\text { Raw material - } \\
\text { hydrogen production } \\
\text { rate }(\mathrm{L} / \mathrm{g})\end{array}$} & \multicolumn{3}{|c|}{$\begin{array}{l}\text { Gasification } \\
\text { efficiency(\%) }\end{array}$} & \multicolumn{3}{|c|}{$\mathrm{H}_{2} \%$} \\
\hline & & & & Results & Result & Results & Results & s Results & Results & Results & Result & Results \\
\hline & & & & $\mathrm{a}$ & $\mathrm{b}$ & C & $\mathrm{a}$ & b & C & $\mathrm{a}$ & $\mathrm{b}$ & C \\
\hline 1 & 973 & 1.5 & $2 \%$ & 0.099 & 0.101 & 0.098 & 43.9 & 43.1 & 43.5 & 39.1 & 39.4 & 39.3 \\
\hline 2 & 1023 & 1.5 & $6 \%$ & 0.151 & 0.148 & 0.150 & 58.0 & 58.2 & 57.7 & 42.5 & 42.7 & 42.1 \\
\hline 3 & 1073 & 1.5 & $8 \%$ & 0.175 & 0.177 & 0.174 & 70.7 & 70.3 & 70.4 & 46.3 & 45.6 & 46.1 \\
\hline 4 & 973 & 2 & $6 \%$ & 0.103 & 0.102 & 0.104 & 49.5 & 49.3 & 49.6 & 43.7 & 43.4 & 43.2 \\
\hline 5 & 1023 & 2 & $8 \%$ & 0.156 & 0.153 & 0.154 & 61.6 & 61.1 & 61.3 & 47.5 & 47.1 & 46.8 \\
\hline 6 & 1073 & 2 & $2 \%$ & 0.181 & 0.177 & 0.179 & 72.7 & 72.5 & 72.8 & 47.9 & 47.7 & 47.6 \\
\hline 7 & 973 & 2.5 & $8 \%$ & 0.101 & 0.102 & 0.104 & 49.8 & 49.4 & 49.6 & 41.2 & 41.5 & 40.7 \\
\hline 8 & 1023 & 2.5 & $2 \%$ & 0.150 & 0.151 & 0.147 & 61.0 & 61.1 & 60.5 & 45.2 & 45.3 & 45.5 \\
\hline 9 & 1073 & 2.5 & $6 \%$ & 0.176 & 0.174 & 0.173 & 71.1 & 71.4 & 70.8 & 46.6 & 46.8 & 46.9 \\
\hline
\end{tabular}

The reactions of biomass during the gasification process mainly are as follows:

$$
\begin{gathered}
\mathrm{C}+\mathrm{H}_{2} \mathrm{O} \rightarrow \mathrm{CO}+\mathrm{H}_{2} \Delta \mathrm{H}>0 \\
\mathrm{C}+2 \mathrm{H}_{2} \mathrm{O} \rightarrow \mathrm{CO}_{2}+\mathrm{H}_{2} \Delta \mathrm{H}>0 \\
\mathrm{C}+\mathrm{CO}_{2} \rightarrow 2 \mathrm{CO} \Delta \mathrm{H}>0 \\
\mathrm{CO}+\mathrm{H}_{2} \mathrm{O} \rightarrow \mathrm{CO}_{2}+\mathrm{H}_{2} \Delta \mathrm{H}<0 \\
\mathrm{CH}_{4}+\mathrm{H}_{2} \mathrm{O} \rightarrow \mathrm{CO}+3 \mathrm{H}_{2} \Delta \mathrm{H}>0
\end{gathered}
$$

It can be seen from the experimental results:

(1) When S/B is 2 and the load is $8 \%$, the reaction temperature is $973 \mathrm{~K}, 1023 \mathrm{~K}$ and $1073 \mathrm{~K}$ respectively, hydrogen production rate increases from $0.108 \mathrm{~L} / \mathrm{g}$ to $0.183 \mathrm{~L} / \mathrm{g}$, the gasification efficiency increases from $49.9 \%$ to $72.9 \%$, the hydrogen content increases from $43.8 \%$ to $48.1 \%$. Reaction (1), reaction (2) and reaction (3) are endothermic reactions, the higher temperature is easier to occur for forward reaction of the endothermic reaction, thereby enhancing the hydrogen yield, gasification efficiency and hydrogen concentration.

(2) When the reaction temperature is $1073 \mathrm{~K}$ and the load is $8 \%, \mathrm{~S} / \mathrm{B}$ increases from 1.5 to 2 and then increases to 2.5 , hydrogen production rate increases from $0.176 \mathrm{~L} / \mathrm{g}$ to $0.183 \mathrm{~L} / \mathrm{g}$ and then decreases to $0.178 \mathrm{~L} / \mathrm{g}$, the gasification efficiency increases from $70.6 \%$ to $72.9 \%$ and then decreases to $71.5 \%$, the hydrogen content increases from $46.2 \%$ to $48.1 \%$ and then decreases to $47.1 \% . \mathrm{S} / \mathrm{B}$ can be increased in a certain range, thus the concentration of water vapor is improved, which is conducive to reactions in forward direction and improves the hydrogen yield. When S/B is increased from 2 to 2.5, an excess of the water vapor would lower the reaction temperature, decrease the reaction rate, and lower the hydrogen yield and gasification efficiency. Therefore, the most appropriate value for $\mathrm{S} / \mathrm{B}$ is 2 .

(3) When the reaction temperature is $1073 \mathrm{~K}$ and $\mathrm{S} / \mathrm{B}$ is 2 , loadincreases from $2 \%$ to $6 \%$ and then increases to $8 \%$, hydrogen production rate increases from $0.179 \mathrm{~L} / \mathrm{g}$ to $0.183 \mathrm{~L} / \mathrm{g}$, the gasification efficiency increases from $72.7 \%$ to $72.9 \%$, the hydrogen content increases from $47.8 \%$ to 
48.1\%.The experimental results show that the productivity of hydrogen,gasification efficiency and hydrogen concentration ascend with the increaseof $\mathrm{Ni}$ load of the catalyst.The catalyst can accelerate the reaction rate and reduce the activation energy of the reaction.

\section{Effect of Catalysts under Different Preparation Conditions on the Experimental Results}

It is primarily to study the effects of the preparation conditions of the catalyst on hydrogen yield, gasification efficiency and hydrogen concentration in the second part of this experiment. The preparation conditions of the catalyst mainly include three aspects on calcination time, calcination temperature and porosity. The experimental conditions of the reactionare selected to be reaction temperature of $1073 \mathrm{~K}, \mathrm{~S} / \mathrm{B}$ of 2 , and the load of $8 \%$, and conduct the orthogonal experiment. The experimental scheme and experimental results are shown in table 2.

Table 2Experimental results of different catalyst preparation conditions

\begin{tabular}{|c|c|c|c|c|c|c|c|c|c|c|c|c|}
\hline \multirow{3}{*}{$\begin{array}{l}\text { Experiment } \\
\text { number }\end{array}$} & \multirow{3}{*}{$\begin{array}{l}\text { Calcination } \\
\text { time(H) }\end{array}$} & \multirow{3}{*}{$\begin{array}{l}\text { Calcination } \\
\text { temperature }(\mathrm{K})\end{array}$} & \multirow{3}{*}{$\begin{array}{l}\text { Porosity } \\
\text { (ppi) }\end{array}$} & \multicolumn{3}{|c|}{$\begin{array}{l}\text { Raw material - } \\
\text { hydrogen production } \\
\text { rate }(\mathrm{L} / \mathrm{g})\end{array}$} & \multicolumn{3}{|c|}{$\begin{array}{c}\text { Gasification } \\
\text { efficiency (\%) }\end{array}$} & \multicolumn{3}{|c|}{$\mathrm{H}_{2} \%$} \\
\hline & & & & \multicolumn{9}{|c|}{ ResultsResultsResultsResultsResultsResultsResultsResultsResults } \\
\hline & & & & $\mathrm{a}$ & $\mathrm{b}$ & C & $\mathrm{a}$ & $\mathrm{b}$ & C & $\mathrm{a}$ & $\mathrm{b}$ & C \\
\hline 1 & 1 & 873 & 10 & 0.161 & 0.159 & 0.162 & 69.7 & 69.5 & 69.8 & 47.5 & 47.2 & 47.4 \\
\hline 2 & 1 & 973 & 20 & 0.177 & 0.176 & 0.173 & 74.1 & 74.2 & 74.4 & 48.7 & 48.5 & 48.9 \\
\hline 3 & 1 & 1073 & 40 & 0.157 & 0.156 & 0.154 & 67.5 & 67.8 & 67.4 & 46.2 & 46.5 & 46.1 \\
\hline 4 & 2 & 873 & 20 & 0.156 & 0.157 & 0.154 & 67.1 & 67.3 & 67.3 & 45.7 & 45.5 & 45.8 \\
\hline 5 & 2 & 973 & 40 & 0.164 & 0.167 & 0.163 & 71.2 & 71.4 & 71.5 & 46.9 & 46.6 & 46.7 \\
\hline 6 & 2 & 1073 & 10 & 0.152 & 0.151 & 0.156 & 66.3 & 66.7 & 66.6 & 44.6 & 44.8 & 44.7 \\
\hline 7 & 3 & 873 & 40 & 0.155 & 0.152 & 0.158 & 67.8 & 67.5 & 67.7 & 45.3 & 45.2 & 45.5 \\
\hline 8 & 3 & 973 & 10 & 0.162 & 0.161 & 0.160 & 69.7 & 69.4 & 69.6 & 46.5 & 46.6 & 46.8 \\
\hline 9 & 3 & 1073 & 20 & 0.149 & 0.146 & 0.148 & 66.5 & 66.3 & 66.7 & 44.8 & 44.6 & 44.7 \\
\hline
\end{tabular}

From the experimental results:

(1) When the calcination temperature is $973 \mathrm{~K}$ and porosity is $20 \mathrm{ppi}$, catalyst calcination time increases from $1 \mathrm{H}$ to $2 \mathrm{H}$ and then increases to $3 \mathrm{H}$, hydrogen production rate decreases from $0.176 \mathrm{~L} / \mathrm{g}$ to $0.163 \mathrm{~L} / \mathrm{g}$, the gasification efficiency decreases from $74.3 \%$ to $70.1 \%$, the hydrogen content decreases from $48.7 \%$ to $46.8 \%$.The experimental results show, that the productivity of hydrogen, gasification efficiency and hydrogen concentration decrease gradually when the calcination time of the catalyst is raised from $1 \mathrm{H}$ to $3 \mathrm{H}$.This is mainly because the calcination time is too long, and the pore structure on the catalyst surface occurs sintering, which makes the specific surface area of the catalyst decreased, and reduces the activity of the catalyst.

(2) The catalyst calcination time is $1 \mathrm{H}$ and porosity is $20 \mathrm{ppi}$, the calcination temperature increases from $873 \mathrm{~K}$ to $973 \mathrm{~K}$ and then increases to $1073 \mathrm{~K}$, hydrogen production rate increases from $0.164 \mathrm{~L} / \mathrm{g}$ to $0.176 \mathrm{~L} / \mathrm{g}$ and then decreases to $0.160 \mathrm{~L} / \mathrm{g}$, the gasification efficiency increases from $70.3 \%$ to $74.3 \%$ and then decreases to $67.9 \%$, the hydrogen content increases from $47.5 \%$ to $48.7 \%$ and then decreases to $46.7 \%$. This is mainly because the calcination temperature must be strictly controlled in the process of calcination of the catalyst so as to gain crystalline phase of the catalyst, grain size, pore structure and specific surface area in a favorable state. Therefore, in order to improve the hydrogen yield, gasification efficiency and hydrogen concentration, the calcination temperature of the catalyst should be within a certain range.

(3) The catalyst calcination time is $1 \mathrm{H}$ and the calcination temperature is $973 \mathrm{~K}$, porosity increases from 10ppi to 20ppi and then increases to 40ppi, hydrogen production rate increases from $0.171 \mathrm{~L} / \mathrm{g}$ to $0.176 \mathrm{~L} / \mathrm{g}$ and then decreases to $0.172 \mathrm{~L} / \mathrm{g}$, the gasification efficiency increases from 
$73.7 \%$ to $74.3 \%$ and then decreases to $73.9 \%$, the hydrogen content increases from $48.2 \%$ to $48.7 \%$ and then decreases to $48.2 \%$. If the porosity of silicon carbide is too narrow, the contact area of the catalyst and the reactants and the contact time will be decreased, impacting on the reaction rate. If the density of silicon carbide is too large, it will contribute to the uneven distribution of the catalyst. Therefore, porosity should be within a reasonable range.

\section{Conclusions}

(1)The reaction temperature has the greatest influence on the hydrogen yield, and the higher reaction temperature is more favorable to improve the hydrogen yield. The most appropriatereaction temperature in this experiment is1073K.The influence of S/B on hydrogen yield is less than that of temperature. S/B should be within a certain range. The most appropriate $\mathrm{S} / \mathrm{B}$ in this experiment is 2 . The influence of load on the hydrogen yield is minimal and it is more favorable for hydrogen production when the load is $8 \%$ in this experiment.

(2)The calcination temperature has the greatest influence on the hydrogen yield. Furthermore, the suitable calcination temperature is more favorable to improve the hydrogen yield, and the calcination temperature is $973 \mathrm{~K}$ in this experiment. The influence of calcination time on the hydrogen yield is less than that of calcination temperature. The calcination time shall be not too long. When calcination time is $1 \mathrm{H}$ in this experiment, the hydrogen can obtain the highest yield. The influence of porosity of the catalyst on the hydrogen yield is minimal and the most suitable porosity is 20ppi in this experiment.

\section{Acknowledgements}

This workwas financially supported by the National Natural Science Foundation of China(51006031).

\section{References}

[1] Carolina Font Palma: Appl. Energy Vol. 111 (2013), p. 129

[2]YafeiShen, KunioYoshikawa: Renew. Sust.Energ. Rev.Vol.21 (2013), p. 371

[3] BaofengZhao, XiaodongZhang and LeiChen: Biomass Bioenergy Vol. 34 (2010), p. 140

[4] FurusawaT, TsutsumiA: Appl. Catal. A Vol. 278 (2005), p. 195

[5] Polychronopoulou K, Bakandritsos A and Tzitzios V: J. Catal. Vol. 241 (2006), p. 132

[6]JianfenLi, RongYan and BoXiao: Environ. Sci. Technol. Vol. 42 (2008), p. 6224

[7] ChangmingXu, Shiwei Wang and Katarina: Ceram. Int. Vol. 36 (2010), p. 923

[8] Xavier Nitsch, Jean-Michel Commandre and Jeremy Valette: Energ. Fuel. Vol. 28 (2014), p. 6936

[9] LigangWei, ShaopingXu and JingangLiu: Energ.Fuel. Vol. 20 (2006), p. 2266

[10] Z. Abu El-Rub, E.A. Bramer and G.brem: Fuel Vol. 87 (2008), p. 2243

[11] Osamu Hirohata, Tomonori Wakabayashi and Kazuhiko Tasaka: Energ. Fuel. Vol.22 (2008), p. 4235

[12] Y. G. Pan, X. Roca and E. Velo: Fuel Vol. 78(1999), p. 1703

[13] Polychronopoulou K, Fierro JLG and EfstathiouAM: J. Catal. Vol. 228 (2004), p. 417 